\title{
Electrophysiologic and Ultrasonographic Assessment of Carpal Tunnel Syndrome in Wheelchair Basketball Athletes
}

\author{
Do Kyun Kim, MD ${ }^{1}$, Beom Suk Kim, MD², Min Je Kim, MD ${ }^{1}$, Ki Hoon Kim, MD, PhD ${ }^{1}$, \\ Byung Kyu Park, MD, $\mathrm{PhD}^{1}$, Dong Hwee Kim, $\mathrm{MD}, \mathrm{PhD}^{1}$ \\ ${ }^{1}$ Department of Physical Medicine \& Rehabilitation, College of Medicine, Korea University, Seoul; \\ ${ }^{2}$ Department of Physical Medicine and Rehabilitation, Army Hospital, Daejeon, Korea
}

\begin{abstract}
Objective To investigate the contributing factors of carpal tunnel syndrome (CTS), electrodiagnostic and ultrasonographic findings of median nerve, and median nerve change after exercise in wheelchair basketball (WCB) players.

Methods Fifteen WCB players with manual wheelchairs were enrolled in the study. Medical history of the subjects was taken. Electrodiagnosis and ultrasonography of both median nerves were performed to assess CTS in WCB players. Ultrasonographic median nerves evaluation was conducted after wheelchair propulsion for 20 minutes. Results Average body mass index (BMI) and period of wheelchair use of CTS subjects were greater than those of normal subjects. Electrodiagnosis revealed CTS in 14 of 30 hands (47\%). Cross-sectional area (CSA) of median nerve was greater in CTS subjects than in normal subjects at $0.5 \mathrm{~cm}$ and $1 \mathrm{~cm}$ proximal to distal wrist crease (DWC), DWC, $1 \mathrm{~cm}, 2 \mathrm{~cm}, 3 \mathrm{~cm}$, and $3.5 \mathrm{~cm}$ distal to DWC. After exercising, median nerve CSAs at $0.5 \mathrm{~cm}$ and 1 $\mathrm{cm}$ proximal to DWC, DWC, and $3 \mathrm{~cm}$ and $3.5 \mathrm{~cm}$ distal to DWC were greater than baseline CSAs in CTS subjects; and median nerve CSAs at $1 \mathrm{~cm}$ proximal to DWC and DWC were greater than baseline CSAs in normal subjects. The changes in median nerve CSA after exercise in CTS subjects were greater than in normal subjects at $0.5 \mathrm{~cm}$ proximal to DWC and $3 \mathrm{~cm}$ and $3.5 \mathrm{~cm}$ distal to DWC.

Conclusion BMI and total period of wheelchair use contributed to developing CTS in WCB players. The experimental exercise might be related to the median nerve swelling around the inlet and outlet of carpal tunnel in WCB athletes with CTS.
\end{abstract}

Keywords Wheelchair basketball, Carpal tunnel syndrome, Electromyography, Ultrasonography

Received February 19, 2016; Accepted July 15, 2016

Corresponding author: Dong Hwee Kim

Department of Physical Medicine and Rehabilitation, Korea University Ansan Hospital, College of Medicine, Korea University, 123 Jeokgeum-ro, Danwon-gu, Ansan 15355, Korea. Tel: +82-31-412-5330, Fax: +82-31-412-5344, E-mail: rmkdh@korea.ac.kr

ORCID: Do Kyun Kim (http://orcid.org/0000-0002-3257-6683); Beom Suk Kim (http://orcid.org/0000-0003-4972-9508); Min Je Kim (http://orcid. org/0000-0003-3794-2192); Ki Hoon Kim (http://orcid.org/0000-0002-7257-3858); Byung Kyu Park (http://orcid.org/0000-0001-8445-7099); Dong Hwee Kim (http://orcid.org/0000-0002-8116-0078).

(c) This is an open-access article distributed under the terms of the Creative Commons Attribution Non-Commercial License (http://creativecommons.org/ licenses/by-nc/4.0) which permits unrestricted noncommercial use, distribution, and reproduction in any medium, provided the original work is properly cited. Copyright $\odot 2017$ by Korean Academy of Rehabilitation Medicine 


\section{INTRODUCTION}

In general, people with disabilities experience psychosocial well-being if they participate in sports games [1]. Wheelchair basketball (WCB) is one of the popular sports among paraplegic patients on wheelchairs. However, general paraplegic patients on wheelchair experience upper extremity pain, especially in shoulder, wrist, and hand joints, due to over-propelling of wheelchairs $[2,3]$. Participating in WCB requires constant flexion and extension of wrists for wheelchair propulsion; and such repeated action could contribute to increase of carpal tunnel syndrome (CTS) because it tends to intensify carpal tunnel pressure [4]. Past studies indicate that prevalence of CTS in paraplegic patients ranges from $40 \%$ to $79 \%$ [58]. CTS could be the underlining cause of pain in distal forearms of WCB players $[9,10]$. Few studies have been conducted on CTS in WCB players, despite their excessive use of wrists.

The purpose of this study was to analyze the demographics and prevalence of CTS in WCB players via electrophysiologic evaluation and ultrasonographic examination. In particular, we determined the effect of wheelchair propulsion exercises on acute median nerve swelling.

\section{MATERIALS AND METHODS}

\section{Subjects}

Fifteen WCB players of Korea Wheelchair Basketball Federation were enrolled (total 30 hands). All subjects had used manual wheelchairs as their primary transportation method for $>10$ years, and had participated in WCB for $>5$ years.

Persons with previous history of peripheral neuropathy of upper extremity or impaired hand function due to trauma, systemic diseases, brain injury, cervical cord injury, past operation history of carpal tunnel release were excluded from the study. All participants provided informed consent before the study. This study was approved by the Institutional Review Board.

\section{Methods}

All subjects completed Boston Carpal Tunnel Questionnaire (BCTQ) as a pre-assessment of severity of symptoms and functional status [11]. Series of physical examinations were conducted on thenar muscle wasting, thumb abduction power, and hypoesthesia of hand, including Phalen and Tinel tests. Electrodiagnosis and ultrasonography were used to evaluate both median nerves.

The Viking Select EMG NCS machine (Nicolet/Viasys, Madison, WI, USA) was used for the electrodiagnostic study. For the median motor conduction study, an active electrode was set on the thenar eminence. The median nerve was stimulated at the wrist $(8 \mathrm{~cm}$ proximal to the active electrode) and at the medial aspect of the antecubital fossa. For the median sensory conduction study, we set an active electrode on the proximal phalanx of 3rd digit and a reference electrode at $4 \mathrm{~cm}$ distal to the active electrode. Stimulation was done $14 \mathrm{~cm}$ and $7 \mathrm{~cm}$ proximal to the active electrode.

In median motor conduction study, onset latency, amplitude, and conduction velocity were obtained. Parameters analyzed in the median sensory conduction study included onset latency, peak latency, and baseline to peak amplitude.

Diagnosis of carpal tunnel syndrome was based on the following criteria: (1) median peak latency of $>3.7 \mathrm{~ms}$; (2) sensory nerve action potential (SNAP) peak latency longer in the proximal $7-\mathrm{cm}$ segment than in the distal 7-cm segment; (3) SNAP amplitude $<20 \mu \mathrm{V}$ and conduction block with a SNAP amplitude decrease of $>50 \%$ with wrist stimulation compared to palm stimulation; (4) 5-cm transcarpal conduction time of $>1.3 \mathrm{~ms}$; (5) median compound motor action potential (CMAP) distal latency of $>4.2 \mathrm{~ms}$; (6) CMAP amplitude of $<4.5 \mathrm{mV}$; and (7) CMAP onset latency differences between the 2nd lumbrical muscle and interosseous muscle $\geq 0.5 \mathrm{~ms}$. Based on modified criteria by Stevens [12], diagnosed CTS patients were graded as mild, moderate, or severe: (1) mild CTSprolonged (relative or absolute) sensory or mixed nerve action potential (NAP) distal latency (orthodromic, antidromic, or palmar) with or without SNAP amplitude below the lower normal limit; (2) moderate CTS-abnormal median sensory latencies as above, and (relative or absolute) prolongation of the median motor CMAP distal latency; (3) severe CTS-prolonged median CMAP and SNAP distal latencies, with either an absent SNAP or mixed NAP, or a low-amplitude or absent thenar CMAP. Needle examination often reveals fibrillations, reduced recruitment, and changes in the motor unit potential. 
Inching test was performed with multi-electrodes stimulator, TenElectrodes, to evaluate the focal lesion site of the median nerve around the wrist $[13,14]$. Ultrasonographic evaluation of both median nerves were performed at 8 different sites of the both upper extremities using the Accuvix V20 Prestige's ultrasound imaging system (Samsung Medison, Seoul, Korea); distal wrist crease (DWC), $0.5 \mathrm{~cm}$ proximal to DWC (DWC+0.5), 1 $\mathrm{cm}$ proximal to DWC (DWC+1), $10 \mathrm{~cm}$ proximal to DWC (DWC+10), $1 \mathrm{~cm}$ distal to DWC (DWC-1), $2 \mathrm{~cm}$ distal to DWC (DWC-2), $3 \mathrm{~cm}$ distal to DWC (DWC-3), and $3.5 \mathrm{~cm}$ distal to DWC (DWC-3.5). The location of DWC+1 cm, DWC $+0.5 \mathrm{~cm}$ and DWC indicated the inlet of carpal tunnel, and DWC-3 cm and DWC-3.5 cm meant the outlet of carpal tunnel. Ultrasonographic evaluation was done in sitting position with the elbow flexed at $90^{\circ}$ and forearm supinated. The investigator measured the CSA of the median nerve. Then, wheelchair propulsion exercise in figure 8 course of about $30 \mathrm{~m}$ was done for 20 minutes with sustainable and submaximal speed (Fig. 1). Sprint test and figure 8 test were combined as an experimental exercise, which includes various movements such as starting, stopping, straight propulsion and changing of directions, as previously described [15-17]. At the end of the exercise, ultrasonographic evaluation of both median nerves was repeated.

\section{Statistical analysis}

SPSS ver. 20 for windows (SPSS Inc., Chicago, IL, USA) was used for the statistical analysis. Mann-Whitney test was used to compare the demographics between subjects with and without CTS. The Spearman correlation coefficient $(\rho)$ between CSA and electrophysiologic parameters

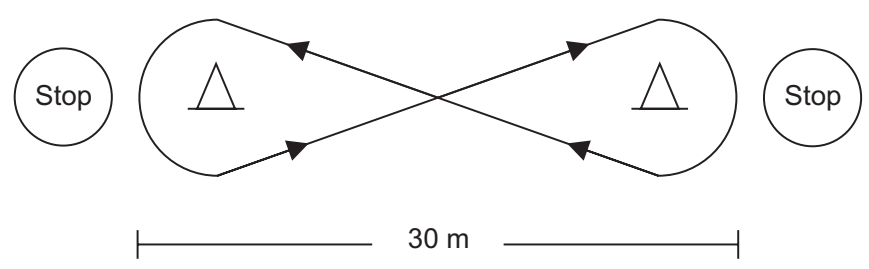

Fig. 1. Schematic drawing of experimental figure 8 exercise course. Wheelchair propulsion exercise in figure 8 course of about $30 \mathrm{~m}$ was done for 20 minutes with sustainable and submaximal speed. When the wheelchair basketball players changed their direction at the end of the course, they stopped in a moment for braking. was measured. Wilcoxon signed-rank test was used to compare the differences of median nerve CSA change in subjects with CTS and normal patients before and after experimental exercise. The significance level was set at $p$ value $<0.05$.

\section{RESULTS}

Fifteen WCB players were enrolled in the study. All subjects were male with a median age of 40 years (range, 2754 years) being. In average, years of wheelchair use was 15 years and WCB career was 11 years. Twelve subjects were paraplegic patients due to lumbar spinal cord injury and 3 subjects were lower extremity amputee. Five of 15 (33\%) participants had $\geq 1$ symptoms of CTS-tingling sense, hypesthesia of hand, night pain and subjective weakness of grasping small object. Seven of 15 (47\%) patients showed abnormal physical examination such as Tinel sign and Phalen sign and objective sensory change or motor weakness of abductor pollicis brevis muscle; and 7 of 15 (47\%) participants were diagnosed as bilateral CTS of mild degree with electrophysiologic evidence. Average body mass index (BMI) of subjects with CTS was greater than that of normal subjects $\left(26.0 \mathrm{~kg} / \mathrm{m}^{2}\right.$ in CTS subjects and $23.4 \mathrm{~kg} / \mathrm{m}^{2}$ in normal; $\left.\mathrm{p}=0.04\right)$. In average, CTS subjects used wheelchair longer than normal subjects (25 years in CTS subjects and 14.5 in normal; $\mathrm{p}=0.014$ ). Between CTS subjects and normal subjects, there was no significant difference in height, wheelchair propelling time and distance per day, years of playing basketball, WCB training time during a week, symptom severity scale of BCTQ. However, subjects with CTS showed higher functional status scale score of BCTQ than normal subjects (2 in CTS subjects and 0 in normal; $\mathrm{p}=0.002$ ) (Table 1 ).

Inching test was done to identify abnormal conduction delay of median nerve in 7 CTS subjects. Most common site of abnormal conduction delay was between $3 \mathrm{~cm}$ and $4 \mathrm{~cm}$ distal to the wrist crease (87.5\%).

Ultrasonographic finding revealed greater median nerve CSA of subject with CTS at $1 \mathrm{~cm}$ and $0.5 \mathrm{~cm}$ proximal to DWC, DWC, $1 \mathrm{~cm}, 2 \mathrm{~cm}, 3 \mathrm{~cm}$ and $3.5 \mathrm{~cm}$ distal to DWC than that of normal subjects (Table 2).

Onset latency of median CMAP showed significant correlations with median nerve CSAs from $\mathrm{DWC}+1 \mathrm{~cm}$ to DWC-3 cm, throughout the carpal tunnel including the inlet and outlet of carpal tunnel. Significant correlation 
Table 1. Comparison of variables in CTS group and normal athletes

\begin{tabular}{lccc}
\hline \multicolumn{1}{c}{ Variable } & CTS (n=7) & Non-CTS (n=8) & p-value \\
\hline Age $(\mathrm{yr})$ & $42(27-54)$ & $39(29-45)$ & 0.336 \\
Body weight $(\mathrm{kg})$ & $75(60-89)$ & $72(49-103)$ & 0.536 \\
\hline Body height $(\mathrm{m})$ & $1.70(1.60-1.80)$ & $1.79(1.70-1.80)$ & 0.072 \\
BMI $\left(\mathrm{kg} / \mathrm{m}^{2}\right)$ & $26.0(23.4-27.5)$ & $23.4(17.6-30.8)$ & $0.040^{*}$ \\
Duration of wheelchair use (yr) & $25.0(14-35)$ & $14.5(6-25)$ & $0.014^{*}$ \\
Years competed (yr) & $11(5-20)$ & $9(6-20)$ & 0.232 \\
\hline Time propelling wheelchair during a day (hr/day) & $10(4-14)$ & $8(1-17)$ & 0.613 \\
Distance wheeled during a day (km/day) & $3(2-5)$ & $2(1-4)$ & 0.121 \\
Training time during a week (hr/wk) & $6(4-7.5)$ & $6(4-8)$ & 0.536 \\
Symptom severity scale & $8(0-11)$ & $4(2-11)$ & 0.094 \\
\hline Functional status scale & $2(1-4)$ & $0(0-1)$ & $0.002^{*}$ \\
\hline
\end{tabular}

Values are presented as median (range).

BMI, body mass index; CTS, carpal tunnel syndrome.

${ }^{*} \mathrm{p}<0.05$.

Table 2. Comparison of CSA $\left(\mathrm{cm}^{2}\right)$ of median nerve between CTS group and normal athletes

\begin{tabular}{cccc}
\hline Image level & CTS $(\mathbf{n}=\mathbf{1 4})$ & Non-CTS $(\mathbf{n}=\mathbf{1 6})$ & p-value \\
\hline DWC+10 & $0.07(0.05-0.14)$ & $0.07(0.05-0.13)$ & 0.313 \\
DWC+1 & $0.12(0.08-0.19)$ & $0.07(0.05-0.12)$ & $0.000^{*}$ \\
DWC+0.5 & $0.12(0.09-0.17)$ & $0.10(0.06-0.12)$ & $0.001^{*}$ \\
DWC & $0.12(0.09-0.18)$ & $0.09(0.06-0.11)$ & $0.000^{*}$ \\
DWC-1 & $0.12(0.08-0.19)$ & $0.10(0.08-0.12)$ & $0.013^{*}$ \\
DWC-2 & $0.12(0.07-0.15)$ & $0.10(0.06-0.12)$ & $0.043^{*}$ \\
DWC-3 & $0.13(0.07-0.23)$ & $0.10(0.06-0.14)$ & $0.031^{*}$ \\
DWC-3.5 & $0.14(0.08-0.23)$ & $0.10(0.07-0.15)$ & $0.010^{*}$ \\
\hline
\end{tabular}

Values are presented as median (range).

CSA, cross-sectional area; CTS, carpal tunnel syndrome; DWC, distal wrist crease.

${ }^{*} \mathrm{p}<0.05$.

was observed between onset latency of median CMAP and median nerve CSAs around the inlet of carpal tunnel and middle area of carpal tunnel adjacent to the inlet of carpal tunnel $(\mathrm{p}<0.01)$ than around outlet of carpal tunnel or middle area of carpal tunnel adjacent to the outlet of carpal tunnel $(\mathrm{p}<0.05)$. The peak latency of median SNAP and median nerve CSA showed correlation in DWC +1, DWC +0.5 , and DWC, around the inlet of carpal tunnel. The amplitude of median CMAP and the latency of median SNAP were negatively correlated with median nerve CSAs around distal to DWC in limited range (Table 3 ).

After 20 minutes of experimental propulsion exercise, CSA of median nerve in all subjects was checked repeatedly with ultrasonography. After exercise, CSAs of median nerve at $0.5 \mathrm{~cm}$ and $1 \mathrm{~cm}$ proximal to DWC, DWC, 3 $\mathrm{cm}$ and $3.5 \mathrm{~cm}$ distal to DWC were greater than pre-exercise median nerve CSAs in subjects with CTS. Also, CSAs of median nerve at $1 \mathrm{~cm}$ proximal to DWC and DWC were greater than pre-exercise median nerve CSAs in normal subjects (Table 4).

The changes in median nerve CSA after exercise in CTS subjects were statistically greater than in normal subjects at $0.5 \mathrm{~cm}$ proximal to DWC and $3 \mathrm{~cm}, 3.5 \mathrm{~cm}$ distal to DWC (Table 4).

\section{DISCUSSION}

WCB is one of the most popular sports among paraplegic patients on wheelchairs. Many paraplegic patients or lower limb amputees depend on manual wheelchair as 
Table 3. Coefficients for the correlations between median nerve CSA and electrophysiologic parameters of median nerve

\begin{tabular}{lccccc}
\hline \multirow{2}{*}{ Image level } & \multicolumn{2}{c}{ CMAP } & & \multicolumn{2}{c}{ SNAP } \\
\cline { 2 - 3 } \cline { 5 - 6 } & Onset latency & Amplitude & & Peak latency & Amplitude \\
\hline DWC+10 & 0.226 & -0.190 & & 0.185 & -0.282 \\
DWC+1 & $0.475^{* *}$ & 0.071 & & $0.506^{* *}$ & 0.012 \\
DWC+0.5 & $0.506^{* *}$ & -0.059 & & $0.545^{* *}$ & -0.137 \\
DWC & $0.488^{* *}$ & -0.075 & & $0.484^{* *}$ & -0.117 \\
DWC-1 & $0.578^{* *}$ & -0.192 & & 0.265 & -0.094 \\
DWC-2 & $0.446^{*}$ & $-0.508^{* *}$ & & 0.332 & $-0.376^{*}$ \\
DWC-3 & $0.378^{*}$ & $-0.361^{*}$ & & 0.293 & -0.334 \\
DWC-3.5 & 0.314 & -0.319 & 0.278 & -0.322 \\
\hline
\end{tabular}

CSA, cross-sectional area; CMAP, compound motor action potential; SNAP, sensory nerve action potentials; DWC, distal wrist crease.

${ }^{*} \mathrm{p}<0.05,{ }^{* *} \mathrm{p}<0.01$.

Table 4. Comparison of CSA $\left(\mathrm{cm}^{2}\right)$ of median nerve in CTS group and normal athletes before and after exercise

\begin{tabular}{|c|c|c|c|c|c|}
\hline \multirow{2}{*}{ Image level } & \multicolumn{2}{|c|}{ Non-CTS $(n=16)$} & \multicolumn{2}{|c|}{ CTS $(n=14)$} & \multirow{2}{*}{ p-value ${ }^{\text {b) }}$} \\
\hline & Pre-exercise & Post-exercise & Pre-exercise & Post-exercise & \\
\hline DWC +10 & $0.07(0.05-0.11)$ & $0.08(0.05-0.13)$ & $0.07(0.05-0.13)$ & $0.07(0.05-0.14)$ & 0.158 \\
\hline DWC+1 & $0.07(0.05-0.12)$ & $0.09(0.07-0.12)^{a) *}$ & $0.12(0.08-0.19)$ & $0.15(0.08-0.23)^{\mathrm{a}) *}$ & 0.525 \\
\hline DWC+0.5 & $0.10(0.06-0.12)$ & $0.10(0.07-0.13)$ & $0.12(0.09-0.17)$ & $0.14(0.12-0.25)^{\mathrm{a}) *}$ & $0.001^{* *}$ \\
\hline DWC & $0.09(0.06-0.11)$ & $0.10(0.07-0.14)^{a) *}$ & $0.12(0.09-0.18)$ & $0.15(0.12-0.21)^{\mathrm{a}) *}$ & 0.052 \\
\hline DWC-1 & $0.10(0.08-0.12)$ & $0.11(0.08-0.17)$ & $0.12(0.08-0.19)$ & $0.12(0.08-0.20)$ & 0.886 \\
\hline DWC-2 & $0.10(0.06-0.12)$ & $0.10(0.08-0.15)$ & $0.12(0.07-0.14)$ & $0.12(0.10-0.15)$ & 0.697 \\
\hline DWC-3 & $0.10(0.06-0.14)$ & $0.11(0.09-0.18)$ & $0.13(0.07-0.23)$ & $0.18(0.13-0.36)^{\mathrm{a}) *}$ & $0.001^{* *}$ \\
\hline DWC-3.5 & $0.10(0.07-0.15)$ & $0.11(0.08-0.18)$ & $0.14(0.08-0.23)$ & $0.20(0.14-0.43)^{\mathrm{a}) *}$ & $0.001^{* *}$ \\
\hline
\end{tabular}

Values are presented as median (range).

CSA, cross sectional area; CTS, carpal tunnel syndrome; DWC, distal wrist crease.

a) indicates a significant difference of median nerve change between pre-exercise and post-exercise groups.

${ }^{b)}$ indicates a significant difference of greater median nerve CSA change in CTS group than in normal athletes.

${ }^{*} \mathrm{p}<0.05,{ }^{* *} \mathrm{p}<0.01$.

a primary means of transportation. Although both upper extremities mainly function as a non-weight-bearing limbs, use of manual wheelchair requires highly repetitive wrist motion for propulsion [18]. Propulsion skills differ between WCB and rehabilitative setting. Playing in WCB engages patients in more extensive wrist motions, such as pivoting, sprinting, and/or braking $[15,19]$. Previous studies have shown that prevalence of CTS in general paraplegic patients varies from $40 \%$ to $79 \%$ [58]. Contrary to initial expectation, prevalence of CTS in WCB players with constant and stressful wrist activities showed little significant difference, as compared to general paraplegic patients.
Among subjected WCB players, only 14 of 30 hands (47\%) were electrophysiologically diagnosed with CTS. Despite the limited number of published studies on correlations between CTS in wheelchair athletes, previous results show similar prevalence of CTS in wheelchair athletes and other paraplegic patients on wheelchair. One study reported a $52 \%$ prevalence of CTS in WCB players, similar to that in general paraplegic patients [20]. Another study indicated prevalence of CTS of approximately $50 \%$ in wheelchair racers [21]. Dozono et al. [22] reported similar prevalence of CTS in wheelchair marathon racers and other patients on wheelchair, which is approximately $10 \%$. Likewise, our study findings also showed that the 
prevalence of CTS in WCB players and other paraplegic patients were not significantly different. Nonetheless, prevalence of CTS in our study is likely to be under estimated because general patients with discernible CTS symptoms would avoid participating in sports activities from the beginning.

Despite lack of previous research on the relationship between other wrist movements and development of CTS in WCB players, it is likely that aggressive maneuvering of wheelchairs contributes to aggravating symptoms. Unlike regular basketball games, playing in WCB games requires intensive wrist movements exclusively to propel wheelchairs. Hence, other basketball movements, such as shooting or dribbling, may have comparatively minor effects on wrists.

In our study, CTS patients had higher BMI and longer wheelchair use period than normal subjects. These conditions are common risk factors in other general CTS patients as well. According to a similar study on CTS prevalence in physically fit paraplegics in full wheelchair marathon racing, wheelchair athletes with relatively lighter weight, showed lower prevalence of CTS than general paraplegic patients probably due to less overloading at their wrist [23]. The years of playing basketball and WCB training time during a week did not vary between CTS subjects and normal subjects. Previous studies on the correlation between wheelchair training time and prevalence of CTS were not used as references in this study. The duration of wheelchair use is possibly the major cause of CTS amongst wheelchair athletes. Therefore, in order to reduce the risk among wheelchair athletes, physicians should recommend body weight control and reduced exposure to excessive wheelchair use.

Inching tests of both median nerves were done for the subjects with CTS. The most common site of abnormal conduction delay was between $3 \mathrm{~cm}$ and $4 \mathrm{~cm}$ distal to the wrist crease. This result was similar to a previous study on general CTS patients that suggested the most common site of abnormal conduction delay was $2 \mathrm{~cm}$ and $4 \mathrm{~cm}$ distal to the transcarpal ligament $[24,25]$.

Ultrasonographic evaluation revealed that CSA of median nerve in CTS patients was increased at $1 \mathrm{~cm}$ and $0.5 \mathrm{~cm}$ proximal to DWC, DWC, $1 \mathrm{~cm}, 2 \mathrm{~cm}, 3 \mathrm{~cm}$ and $3.5 \mathrm{~cm}$ distal to DWC compared to normal subjects. This result was indicative of swelling between inlet and outlet of carpal tunnel. Sarria et al. [26] and Nakamichi and
Tachibana [27] reported similar ultrasonographic findings in general CTS patients. Abe [28] reported similar ultrasonographic findings in handicapped person with CTS. However, these studies did not distinguish between paraplegic and hemiplegic patients. In our study, we used electrophysiologic and ultrasonographic assessments to diagnose CTS in WCB players. This was the first attempt to use both methodologies in combination for WCB players.

As a result, there was a correlation between some electrophysiologic parameters and median nerve CSA. Onset latency of median CMAP and median nerve CSA showed correlation throughout the carpal tunnel including the inlet and outlet of carpal tunnel. Higher correlation occurred between onset latency of median CMAP and median nerve CSA around the inlet of carpal tunnel than around another location of carpal tunnel. Peak latency of SNAP and median nerve CSA revealed correlation around inlet of the carpal tunnel. Amplitudes of median CMAP and SNAP showed negative correlation with median nerve CSA in limited range, around distal to DWC. A previous study showed higher correlation between median nerve CSA and distal motor latency around inlet and middle area of carpal tunnel, and between median nerve CSA and sensory conduction velocity around inlet of carpal tunnel [29]. Another study showed a correlation between median nerve CSA and electrophysiologic parameters around inlet of carpal tunnel-onset latency and amplitude of CMAP, peak latency and amplitude of SNAP [30]. Past studies have indicated correlation between median nerve CSA and severity of CTS [30,31]. However, we were unable to detect any correlation due to mild conditions in all CTS subjects.

CSA of median nerve at $0.5 \mathrm{~cm}$ and $1 \mathrm{~cm}$ proximal to DWC, DWC, $3 \mathrm{~cm}$ and $3.5 \mathrm{~cm}$ distal to DWC increased after exercise in CTS subjects. Similarly, in normal subjects, CSA of median nerve at $1 \mathrm{~cm}$ proximal to DWC and DWC increased after exercise. The results suggested that acute propulsion exercise causes acute median nerve swelling around inlet or outlet of carpal tunnel in subjects with CTS and normal subjects. When comparing the level of swelling after exercise, subjects with CTS showed greater difference of median nerve CSA than that of normal patients at $0.5 \mathrm{~cm}$ proximal to DWC and $3 \mathrm{~cm}, 3.5$ $\mathrm{cm}$ distal to DWC. Thus, subjects with CTS showed more significant median nerve change around inlet and outlet 
of carpal tunnel after experimental exercise than normal subjects. Therefore, wheelchair users with CTS are advised to practice precise propelling techniques in addition to body weight control. Although electrophysiologic evaluation was not used to diagnose CTS, Impink et al. [16] reported more significant median nerve change after wheelchair propulsion in subjects with symptoms of CTS rather than normal subjects.

Unlike previous studies, we included sonographic assessment of acute median nerve change after exercise in wheelchair athletes as well as electrophysiologic evaluation before the exercise to diagnose CTS $[16,20]$. Sonographic evaluation was performed at 8 different sites, thus providing more detailed information about median nerve swelling around the carpal tunnel.

Our study had a couple of limitations. Firstly, the sample size was limited to 15 WCB subjects. While our findings corroborate several previous studies, more observations could have shown more definite statistics. Second, although experimental exercise like figure 8 test might have a strenuous tendency than in general wheelchair use, aggravation of CTS in WCB players could not be inferred. General wheelchair propulsion itself is considered more important to develop CTS. And, controlled exercises were limited to wheelchair propelling and braking movements in our subjects. In uncontrolled condition, WCB players would use more complicated movements such as pivoting, braking, and backward propelling. Furthermore, our study included only one ultrasonographic assessment for median nerve swelling after the exercise. Ultrasonographic evaluation after longer time interval between the exercises would have shown mitigated condition.

In conclusion, BMI and total wheelchair use period were the important contributing factors to developing CTS in WCB athletes. Contributing factors related to CTS were similar between WCB players and general paraplegic wheelchair users. Therefore, WCB athletes should be more aware of the importance of body weight control and proper wheelchair propelling technique to prevent CTS. Clinicians may refer to ultrasonographic assessment to measure median nerve swelling and, based on the result, recommend proper use of wheelchairs. Since swelling of median nerve in WCB players with CTS tends to be more severe than in normal WCB players, careful observation of aggravated CTS symptom is needed in WCB athletes.

\section{CONFLICT OF INTEREST}

No potential conflict of interest relevant to this article was reported.

\section{REFERENCES}

1. Campbell E. Psychological well-being of participants in wheelchair sports: comparison of individuals with congenital and acquired disabilities. Percept Mot Skills 1995;81:563-8.

2. Dalyan M, Cardenas DD, Gerard B. Upper extremity pain after spinal cord injury. Spinal Cord 1999;37:191-5.

3. van Drongelen S, de Groot S, Veeger HE, Angenot EL, Dallmeijer AJ, Post MW, et al. Upper extremity musculoskeletal pain during and after rehabilitation in wheelchair-using persons with a spinal cord injury. Spinal Cord 2006;44:152-9.

4. Goodman CM, Steadman AK, Meade RA, Bodenheimer C, Thornby J, Netscher DT. Comparison of carpal canal pressure in paraplegic and nonparaplegic subjects: clinical implications. Plast Reconstr Surg 2001;107:1464-71.

5. Aljure J, Eltorai I, Bradley WE, Lin JE, Johnson B. Carpal tunnel syndrome in paraplegic patients. Paraplegia 1985;23:182-6.

6. Davidoff G, Werner R, Waring W. Compressive mononeuropathies of the upper extremity in chronic paraplegia. Paraplegia 1991;29:17-24.

7. Tun CG, Upton J. The paraplegic hand: electrodiagnostic studies and clinical findings. J Hand Surg Am 1988;13:716-9.

8. Akbar M, Penzkofer S, Weber MA, Bruckner T, Winterstein M, Jung M. Prevalence of carpal tunnel syndrome and wrist osteoarthritis in long-term paraplegic patients compared with controls. J Hand Surg Eur Vol 2014;39:132-8.

9. Curtis KA, Dillon DA. Survey of wheelchair athletic injuries: common patterns and prevention. Paraplegia 1985;23:170-5.

10. Burnham RS, Steadward RD. Upper extremity peripheral nerve entrapments among wheelchair athletes: prevalence, location, and risk factors. Arch Phys Med Rehabil 1994;75:519-24.

11. Levine DW, Simmons BP, Koris MJ, Daltroy LH, Hohl GG, Fossel AH, et al. A self-administered question- 
naire for the assessment of severity of symptoms and functional status in carpal tunnel syndrome. J Bone Joint Surg Am 1993;75:1585-92.

12. Stevens JC. AAEM minimonograph \#26: the electrodiagnosis of carpal tunnel syndrome. American Association of Electrodiagnostic Medicine. Muscle Nerve 1997;20:1477-86.

13. Kang YK, Kim DH, Lee SH, Hwang M, Han MS. Tenelectrodes: a new stimulator for inching technique in the diagnosis of carpal tunnel syndrome. Yonsei Med J 2003;44:479-84.

14. Kim DH, Kang YK, Hwang M, Jo HS, Kim KH. Localization of ulnar neuropathy at the elbow using new stimulator for the inching test. Clin Neurophysiol 2004;115:1021-6.

15. Goosey-Tolfrey V. Wheelchair sport: a complete guide for athletes, coaches, and teachers. Champaign: $\mathrm{Hu}$ man Kinetics; 2010.

16. Impink BG, Collinger JL, Boninger ML. The effect of symptoms of carpal tunnel syndrome on ultrasonographic median nerve measures before and after wheelchair propulsion. PM R 2011;3:803-10.

17. Ergun N, Duzgun I, Aslan E. Effect of the number of years of experience on physical fitness, sports skills and quality of life in wheelchair basketball players. Fizyoterapi Rehabilitasyon 2008;19:55-63.

18. Wei SH, Huang S, Jiang CJ, Chiu JC. Wrist kinematic characterization of wheelchair propulsion in various seating positions: implication to wrist pain. Clin Biomech (Bristol, Avon) 2003;18:S46-52.

19. Curtis KA, Black K. Shoulder pain in female wheelchair basketball players. J Orthop Sports Phys Ther 1999;29:225-31.

20. Jackson DL, Hynninen BC, Caborn DN, McLean J. Electrodiagnostic study of carpal tunnel syndrome in wheelchair basketball players. Clin J Sport Med 1996;6:27-31.

21. Boninger ML, Robertson RN, Wolff M, Cooper RA.
Upper limb nerve entrapments in elite wheelchair racers. Am J Phys Med Rehabil 1996;75:170-6.

22. Dozono K, Hachisuka K, Hatada K, Ogata H. Peripheral neuropathies in the upper extremities of paraplegic wheelchair marathon racers. Paraplegia 1995;33:20811.

23. Asayama K, Nakamura Y, Ogata H, Hatada K, Okuma $\mathrm{H}$, Deguchi Y. Physical fitness of paraplegics in full wheelchair marathon racing. Paraplegia 1985;23:27787.

24. Kimura J. The carpal tunnel syndrome: localization of conduction abnormalities within the distal segment of the median nerve. Brain 1979;102:619-35.

25. Seror P. Orthodromic inching test in mild carpal tunnel syndrome. Muscle Nerve 1998;21:1206-8.

26. Nakamichi K, Tachibana S. Ultrasonographic measurement of median nerve cross-sectional area in idiopathic carpal tunnel syndrome: diagnostic accuracy. Muscle Nerve 2002;26:798-803.

27. Sarria L, Cabada T, Cozcolluela R, Martinez-Berganza T, Garcia S. Carpal tunnel syndrome: usefulness of sonography. Eur Radiol 2000;10:1920-5.

28. Abe M. Ultrasound measurement of the median nerve for carpal tunnel syndrome of the non-handicapped and the handicapped. J Phys Ther Sci 2004;16:107-14.

29. Mondelli M, Filippou G, Gallo A, Frediani B. Diagnostic utility of ultrasonography versus nerve conduction studies in mild carpal tunnel syndrome. Arthritis Rheum 2008;59:357-66.

30. Kwon HK, Kang HJ, Byun CW, Yoon JS, Kang CH, Pyun SB. Correlation between ultrasonography findings and electrodiagnostic severity in carpal tunnel syndrome: 3D ultrasonography. J Clin Neurol 2014;10:348-53.

31. Padua L, Pazzaglia C, Caliandro P, Granata G, Foschini M, Briani C, et al. Carpal tunnel syndrome: ultrasound, neurophysiology, clinical and patient-oriented assessment. Clin Neurophysiol 2008;119:2064-9. 